\title{
ATENÇÃO À SAÚDE DE LÉSBICAS, GAYS, BISSEXUAIS, TRAVESTIS E TRANSEXUAIS NA ESTRATÉGIA SAÚDE DA FAMÍLIA
}

\author{
HEALTH CARE FOR LESBIAN, GAY, BISEXUAL, \\ TRANSVESTITE AND TRANSGENDER INDIVIDUALS IN \\ THE FAMILY HEALTH STRATEGY
}

\section{ATENCIÓN DE SALUD A LESBIANAS, GAYS, BISEXUALES, TRAVESTIS Y TRANSEXUALES EN LA ESTRATEGIA SALUD DE LA FAMILIA}

\author{
Jameson Moreira Belém ${ }^{1}$ \\ Maria Juscinaide Henrique Alves ${ }^{2}$ \\ Emanuelly Vieira Pereira ${ }^{2}$ \\ Felice Teles Lira dos Santos Moreira ${ }^{3}$ \\ Glauberto da Silva Quirino ${ }^{4}$ \\ Grayce Alencar Albuquerque
}

Como citar este artigo: Belém JM, Alves MJH, Pereira EV, Moreira FTLS, Quirino GS, Albuquerque GA. Atenção à saúde de Lésbicas, Gays, Bissexuais, Travestis e Transexuais na Estratégia Saúde da Família. Rev baiana enferm (2018);32:e26475.

Objetivo: analisar a atenção à saúde prestada à população de Lésbicas, Gays, Bissexuais, Travestis e Transexuais na Estratégia Saúde da Família. Método: estudo qualitativo desenvolvido em junho de 2014 com 12 enfermeiros, no interior do Ceará, Brasil, por meio de entrevista semiestruturada. Os dados foram organizados e analisados com base na análise categorial temática e eixos estratégicos da política nacional de saúde integral. Resultados: as ações de promoção e vigilância da saúde eram reducionistas, fragmentadas, enviesadas em função da orientação sexual e afetadas pela baixa assiduidade, estereótipos e barreiras nos atendimentos. Esse contexto era agravado por lacunas na formação acadêmica, qualificação dos profissionais sobre sexualidade e dificuldade de implementação, monitoramento e avaliação da política de saúde. Conclusão: a atenção à saúde prestada à população de Lésbicas, Gays, Bissexuais, Travestis e Transexuais na Estratégia Saúde da Família exige mudanças paradigmáticas desde o âmbito teórico-organizacional às relações de cuidado.

Descritores: Minorias Sexuais. Assistência Integral à Saúde. Desigualdades em Saúde. Enfermagem de Atenção Primária. Atenção Primária à Saúde.

Objective: analyze the health care provided to the lesbian, gay, bisexual, transvestite and transgender population in the Family Health Strategy. Method: qualitative study developed in June 2014 involving 12 nurses, in the interior of the

\footnotetext{
Enfermeiro. Mestre em Enfermagem. Professor Substituto do Departamento de Enfermagem da Universidade Regional do Cariri, Campus do Pimenta. Crato, Ceará, Brasil.jam.ex@hotmail.com

Enfermeira. Mestre em Enfermagem. Professora Temporária da Universidade Regional do Cariri. Crato, Ceará, Brasil.

Enfermeira. Especialista em Auditoria em Sistemas de Saúde. Professora Substituta da Universidade Regional do Cariri. Crato, Ceará, Brasil.

Enfermeiro. Doutor em Educação em Ciências: Química da Vida e Saúde. Professor Adjunto da Universidade Regional do Cariri. Crato, Ceará, Brasil.

Enfermeira. Doutora em Ciências da Saúde. Professora Assistente da Universidade Regional do Cariri. Crato, Ceará, Brasil.
} 
state of Ceará, Brazil, through a semistructured interview. The data were organized and analyzed based on thematic categorical analysis and strategic axes of the Brazilian comprehensive health policy. Results: the health promotion and surveillance actions were reductionist, fragmented, biased in function of the sexual orientation and affected by the low attendance, stereotypes and barriers in care. Gaps in the academic background, in the professionals' qualification about sexuality and difficulties to implement, monitor and assess the health policy aggravated this context. Conclusion: the health care provided to the lesbian, gay, bisexual, transvestite and transgender population in the Family Health Strategy requires paradigmatic changes ranging from the theoretical-organizational sphere to the care relationships.

Descriptors: Sexual Minorities. Comprehensive Health Care. Health Status Disparities. Primary Care Nursing. Primary Health Care.

Objetivo: analizar la atención de salud prestada a la población de lesbianas, gays, bisexuales, travestis y transexuales en la estrategia Salud de la Familia. Método: estudio cualitativo desarrollado en junio de 2014 con 12 enfermeros, en el interior del estado de Ceará, Brasil, mediante entrevista semiestructurada. Los datos fueron organizados y analizados con base en el análisis categorial temático y ejes estratégicos de la política nacional de salud integral. Resultados: las acciones de promoción y vigilancia de salud eran reduccionistas, fragmentadas, sesgadas en función de la orientación sexual y perjudicadas por la baja asistencia, estereotipos y barreras en las atenciones. Ese contexto era agravado por deficiencias en la formación académica, cualificación de los profesionales sobre sexualidad y dificultad de implementación, monitoreo y evaluación de la política de salud. Conclusión: la atención de salud prestada a la población de lesbianas, gays, bisexuales, travestis y transexuales en la estrategia Salud de la Familia demanda cambios paradigmáticos desde el ámbito teórico-organizacional hasta las relaciones de cuidado.

Descriptores: Minorías Sexuales. Atención Integral de Salud. Disparidades en el Estado de Salud. Enfermería de Atención Primaria. Atención Primaria de Salud.

\section{Introdução}

O direito ao acesso universal às ações e serviços de saúde no Brasil encontra-se previsto constitucionalmente desde 1988, com a criação de um Sistema Único de Saúde (SUS), que assegura aos usuários atendimento voltado à promoção, prevenção, diagnóstico, tratamento, cura, recuperação e reabilitação da saúde em todos os níveis e instâncias das redes de atenção ${ }^{(1)}$.

Nesse contexto, a Estratégia Saúde da Família (ESF), como principal eixo estruturante do SUS, é utilizada para fortalecer a Atenção Primária a Saúde (APS) enquanto primeiro nível de atenção, porta de entrada no sistema e ordenadora dos cuidados no SUS, objetivando assegurar a integralidade da atenção aos indivíduos, famílias e coletividades $^{(1)}$.

No entanto, a acessibilidade e o acesso oportuno aos cuidados primários de saúde ainda se constituem um problema em muitos países ${ }^{(2)}$, sobretudo entre populações vulneráveis que vivenciam situações de desigualdades, iniquidades e violações de direitos ${ }^{(3)}$. Essa realidade é comumente vivenciada no contexto da América Latina ${ }^{(4)}$ por Lésbicas, Gays, Bissexuais, Travestis e Transexuais (LGBT), em virtude da não adequação da identidade de gênero ao sexo biológico ou à orientação sexual não heteronormativa ${ }^{(5-6)}$. Esta população, comparada aos indivíduos heterossexuais, enfrenta entraves estruturais, culturais e organizacionais ao deparar-se com barreiras simbólicas, morais e estéticas articuladas a marcadores sociais da diferença, lógicas de exclusão e/ou não aceitação social ${ }^{(7)}$.

Nesse cenário de discriminação, experiências negativas podem ser observadas nos serviços de saúde sob a forma de condutas inadequadas dos profissionais, constrangimentos, ofensas verbais com conotações preconceituosas e estigmatizantes $^{(8)}$, além de atendimentos não humanizados, com ausência de acolhimento, negligência de ações e/ou omissão de cuidado ${ }^{(9)}$. Tais atos, que violam direitos humanos, concorrem para redução da assiduidade, não busca por serviços de saúde e déficit no autocuidado, o que eleva a vulnerabilidade da população LGBT aos agravos em saúde ${ }^{(8)}$. 
Indicadores da situação de saúde-doença dessa população no país apontam elevados índices de violência por homofobia, apesar dos sub-registros (denúncias e notificações) em dados oficiais $^{(10)}$, vulnerabilidade individual, social e programática ao Human Immunodeficiency Virus (HIV)/Acquired Immunodeficiency Syndrome (Aids), sobretudo entre Homens que fazem Sexo com Homens $(\mathrm{HSH})^{(11)}$ e travestis ${ }^{(12)}$, vulnerabilidade aos comportamentos depressivos, ansiedades, medos excessivos, ideações e tentativas de suicídio desde a adolescência ${ }^{(13)}$ até a maturidade e velhice ${ }^{(14)}$, associados a maior risco de uso abusivo de álcool e outras drogas ${ }^{(6)}$.

Assim, em reconhecimento às desfavoráveis condições de saúde que afetam o público LGBT, inúmeras ações e estratégias governamentais foram formuladas e implementadas para reduzir as iniquidades e desigualdades em saúde nesse grupo populacional. Nesse campo específico, cita-se a criação do Conselho Nacional de Combate à Discriminação (2001), o Programa Brasil sem Homofobia (2004), Comitê Técnico de Saúde da População LGBT (2004), Plano Nacional de Enfrentamento da Epidemia de Aids e Doenças Sexualmente Transmissíveis (DST) (2007), Plano Nacional de Enfrentamento da Epidemia de Aids e das DST entre Gays, HSH e Travestis (2007), Processo Transexualizador (2008), Conferência Nacional de LGBT (2008), Plano Nacional de Promoção da Cidadania e Direitos Humanos LGBT (2009), Programa Nacional de Direitos Humanos (2009) e a Política Nacional de Saúde Integral de LGBT (2011) ${ }^{(15)}$.

A Política Nacional de Saúde Integral de LGBT, disposta em quatro eixos estratégicos de atuação, constitui importante marcador que reconhece a orientação sexual e a identidade de gênero como determinantes da saúde, bem como apresenta-se como instrumento norteador das práticas de cuidado para atendimento das necessidades em saúde de modo oportuno, resolutivo e integral desse grupo, com destaque para ações de promoção, vigilância, educação em saúde, monitoramento e acessibilidade, pilares fundamentais e estratégicos de atuação da $\operatorname{ESF}^{(16)}$.
Entretanto, impõem-se desafios enfrentados pelos serviços e profissionais de saúde da APS para compreender, incorporar e atender as demandas e especificidades na organização, oferta de atenção e cuidados ao público LGBT, objetivando-se efetivação de ações de promoção da saúde $^{(17)}$, que, quando não incorporadas no cotidiano de trabalho da ESF, implicam na busca por serviços de atenção secundária, reforçando a lógica hospitalocêntrica pelo público LGBT ${ }^{(8)}$.

Desse modo, objetivou-se analisar a atenção à saúde prestada à população de Lésbicas, Gays, Bissexuais, Travestis e Transexuais (LGBT) na Estratégia Saúde da Família (ESF).

\section{Método}

Estudo exploratório e descritivo com abordagem qualitativa desenvolvido com enfermeiros atuantes na ESF do município de Juazeiro do Norte, localizado na Microrregião do Cariri, Mesorregião Sul do estado do Ceará, Nordeste, Brasil.

A pesquisa obedeceu às exigências éticas e científicas para pesquisas envolvendo seres humanos, definidas na Resolução n. 466/12 do Conselho Nacional de Saúde/Ministério da Saúde, tendo sido aprovada por Comitê de Ética em Pesquisa sob Parecer n. 458.757.

Para inclusão dos participantes do estudo estabeleceram-se como critérios: ser enfermeiro de alguma equipe de Saúde da Família (eSF) do referido município e apresentar exercício profissional mínimo de um ano na equipe à qual estava vinculado durante o período de realização da pesquisa. Este último critério foi estabelecido pelos pesquisadores por considerarem que o referido tempo contempla maior contato com a realidade de saúde da comunidade assistida e o conhecimento de seu perfil sanitário.

A escolha desses profissionais justifica-se pela sua inserção, coordenação e participação em ações e serviços na APS. Além disso, os processos de trabalho e o modo como esses profissionais percebem os contextos de vulnerabilidade, necessidades individuais e coletivas, determinantes e condicionantes de saúde das 
populações vulneráveis podem constituir-se como elementos caracterizadores das práticas em saúde ofertadas a esse público nesse cenário de atenção.

Inicialmente, solicitou-se anuência do departamento de Atenção Básica, órgão gestor da APS, vinculado à Secretaria Municipal de Saúde do município, por meio de termo de autorização para execução da pesquisa. Autorização concedida, procedeu-se ao levantamento dos distritos sanitários, localizados em zona urbana, que congregassem maior número de eSF. Ressalta-se que Juazeiro do Norte (CE) apresentava, em sua configuração assistencial, APS subdividida em seis distritos sanitários (delimitação político-administrativa do território usada para organização do sistema de atenção que congrega quantitativo variável de eSF). No total, durante o período de coleta de dados, estavam distribuídas, nos seis distritos, 66 eSF, perfazendo 87,14\% de cobertura da APS. Após obtenção dos valores, foram realizadas coletas de dados nos distritos sanitários II e V, selecionados por possuírem o maior quantitativo de eSF alocadas na zona urbana.

Em posse das equipes de saúde selecionadas, procedeu-se ao contato pessoal aleatório com os enfermeiros participantes do estudo. Nesse momento, esses foram esclarecidos sobre o desenvolvimento da pesquisa, avaliados quanto aos critérios de inclusão e convidados a participar. A coleta das informações foi realizada em junho de 2014 com data, local e horários prévia e consensualmente definidos, respeitando a disponibilidade do entrevistado e analisando as condições locais para o adequado desenvolvimento da entrevista.

A amostra do estudo contou com a participação de 12 enfermeiros atuantes em eSF, na faixa etária entre 24 a 39 anos de idade (média de 30,3 anos), com predominância do sexo feminino. A maioria dos entrevistados era casada, católica, com renda mensal que variou de dois a seis salários mínimos, sendo a média de 4,2 salários (para cálculo da renda mensal, considerou-se o valor de $\mathrm{R} \$ 678,00$ vigente para o salário mínimo durante o período de realização da pesquisa).

Quanto à formação e ao aprimoramento, oito profissionais possuíam especialização na área de saúde da família, embora a maioria tenha referido nunca ter participado de capacitações voltadas para o atendimento ao público LGBT. No que se refere ao tempo de exercício profissional, sete enfermeiros possuíam tempo de atuação inferior a cinco anos, estando os demais depoentes com tempo de atuação na ESF entre cinco e dez anos.

Para a coleta de informações, recorreu-se à entrevista semiestruturada, adotando-se, durante sua aplicação, procedimentos ou medidas de minimização dos desconfortos e riscos previsíveis, garantindo o sigilo das informações pessoais obtidas e anonimato dos participantes, por meio da adoção de códigos para omitir dados que permitissem a identificação.

Ressalta-se que as falas foram gravadas em áudio, com expressa autorização dos depoentes por meio de assinatura do Termo de Consentimento Livre e Esclarecido (TCLE) e, posteriormente, transcritas na íntegra. O processo de coleta de dados encerrou-se após identificação da saturação teórica dos discursos ${ }^{(18)}$.

As informações obtidas foram organizadas segundo a análise categorial temática. Seguiram-se as etapas de pré-análise, exploração do material e tratamento dos resultados, utilizando-se procedimentos sistemáticos e objetivos de descrição do conteúdo das mensagens ${ }^{(19)}$. No entanto, levou-se em consideração flexibilidade e sensibilidade dos pesquisadores quanto à alocação dos discursos nas categorias e subcategorias.

Os resultados foram apresentados citando-se trechos das respostas, identificados por meio da utilização de códigos compostos pela abreviatura da palavra enfermeiro (Enf.), seguida de um número que representa a ordem de realização das entrevistas. Posteriormente foram discutidos em associação com a literatura pertinente e analisados de forma interpretativa com base nos quatro eixos estratégicos contidos do plano operativo da Política Nacional de Saúde Integral de LGBT $^{(16)}$. 


\section{Resultados}

No eixo 1 da Política Nacional de Saúde Integral de LGBT intitulado "acesso da população LGBT à atenção integral à saúde", os participantes expressaram que esse grupo apresentava baixa adesão às ações e reduzida assiduidade aos serviços de saúde relacionadas ao receio de sofrer discriminação e preconceito pelos usuários da ESF e pelos profissionais. Os integrantes do grupo LGBT são percebidos como não pertencentes aos espaços das unidades básicas de saúde, conforme evidenciado no fragmento " $A$ unidade básica não é lugar para eles. (Enf. 5)", sobretudo pelo comportamento ansioso, problemas mentais e Infecções Sexualmente Transmissíveis (IST). Além disso, independente da sua expressão ou não, a orientação sexual é referida como empecilho à comunicação entre usuários LGBT e enfermeiros.

Quadro 1 - Categorias temáticas relativas ao eixo "acesso da população de Lésbicas, Gays, Bissexuais, Travestis e Transexuais à atenção integral à saúde”. Juazeiro do Norte, Ceará, Brasil - 2018 (continua)

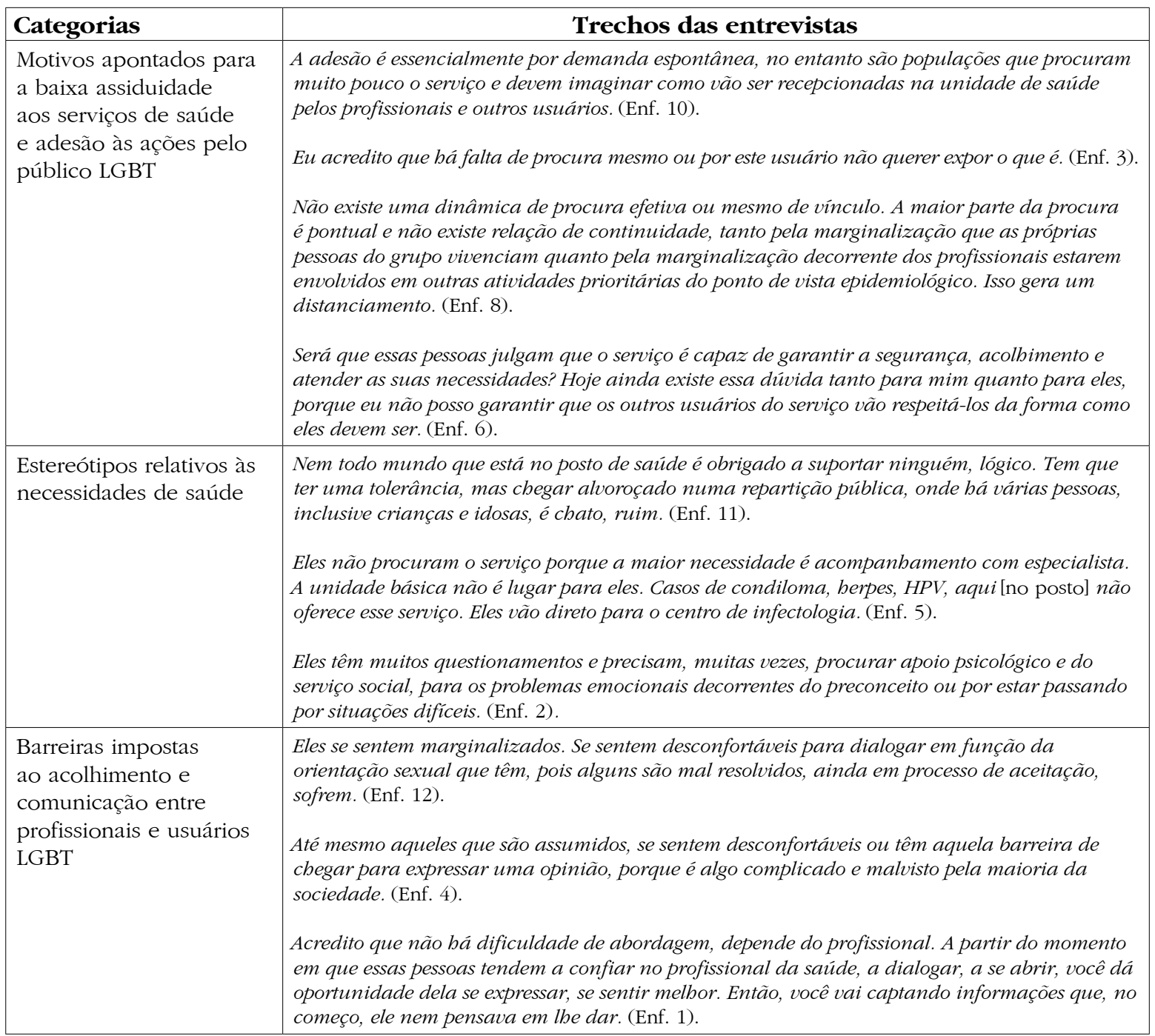

Fonte: Elaboração própria.

No eixo 2 da Política Nacional de Saúde Integral de LGBT relativo às "ações de promoção e vigilância em saúde para a população LGBT", evidenciou-se um direcionamento aos comportamentos de risco alicerçados em uma concepção comparativa entre heterossexuais e homossexuais. No entendimento dos profissionais, as ações devem ser voltadas para as vulnerabilidades, IST e aspectos psicológicos, sendo a orientação sexual não heterossexual 
determinante para o desenvolvimento de estratégias voltadas a esse público. Em decorrência disso, os profissionais destacaram a necessidade de busca ativa com auxílio dos Agentes
Comunitários de Saúde (ACS) e formação de grupos específicos para educação em saúde com apoio de outros serviços.

Quadro 2 - Categorias temáticas relativas ao eixo "ações de promoção e vigilância em saúde para a população de Lésbicas, Gays, Bissexuais, Travestis e Transexuais”. Juazeiro do Norte, Ceará, Brasil - 2018

(continua)

\begin{tabular}{|c|c|}
\hline Categorias & Trechos das entrevistas \\
\hline $\begin{array}{l}\text { Ações em saúde } \\
\text { construídas com base } \\
\text { na concepção de } \\
\text { grupo de risco }\end{array}$ & $\begin{array}{l}\text { Não podemos desvincular a noção de risco. Apesar de ter mudado muito o perfil epidemiológico das } \\
\text { doenças sexualmente transmissíveis, há um padrão ainda, porque são pessoas que bebem muito, } \\
\text { estão em ambientes festivos, locais alternativos e vulneráveis às doenças sexualmente transmissíveis } \\
\text { por conta da associação ao álcool e pelo próprio preconceito alguns se submetem a fazer relação } \\
\text { sem proteção, porque se sentem minimizados ou inferiorizados. Então, por esse ambiente que eles } \\
\text { são obrigados a conviver, às vezes, mais excluídos, eles continuam sendo um grupo de risco, por ser } \\
\text { uma população exposta à vulnerabilidade social, às violências e crimes sexuais. (Enf. 9). } \\
\text { Independente se a pessoa é homossexual ou heterossexual, se você tem muitos parceiros, a } \\
\text { probabilidade de você adquirir uma doença sexualmente transmissível é enorme. Então todo } \\
\text { mundo hoje faz parte do grupo de risco. (Enf. 3). } \\
\text { Essas pessoas têm as mesmas necessidades da população em geral, mas acrescidas de outras } \\
\text { coisas especificas, como urologista, exame de HIV com mais frequência, se ele for submetido a } \\
\text { comportamentos de risco frequentes. (Enf. 7). }\end{array}$ \\
\hline $\begin{array}{l}\text { Ações de cuidado } \\
\text { enviesadas em } \\
\text { função de orientação } \\
\text { sexual não } \\
\text { heterossexual }\end{array}$ & $\begin{array}{l}\text { Quando eles vêm à procura é porque estão com alguma sintomatologia clinica, e o nosso papel é } \\
\text { identificar o problema e a liberação do preservativo junto com a educação em saúde na consulta. } \\
\text { (Enf. 11). } \\
\text { Eu não queria trabalhar com esse grupo, porque é tão complexo. Não só envolve doenças sexuais, } \\
\text { mas sentimentos, triângulo amoroso, tantas coisas que seria a última coisa que eu queria trabalhar. } \\
\text { Eu não gosto, não vou mentir. (Enf. 1). } \\
\text { Se eles forem abertamente declarados, eu não posso tratar a sexualidade de uma mulher } \\
\text { beterossexual do mesmo jeito que eu trato a sexualidade de uma mulher lésbica. São mundos } \\
\text { diferentes. (Enf. 9). } \\
\text { os pacientes homossexuais que eu tratei eram portadores de HIV e tuberculose, porque eles } \\
\text { praticaram sexo sem proteção, para não perder o parceiro, porque são individuos altamente } \\
\text { carentes, por uma consequência de vida de exclusão, de preconceito, violência psicológica e física. } \\
\text { Então minhas ações seriam praticamente voltadas para o acolbimento, fortificar as questões dos } \\
\text { direitos da cidadania, prevenir as IST, diminuir a incidência de alcoolismo e associação com o uso } \\
\text { de outras drogas, sublinhar a autoestima, superação da violência e promoção da cultura de paz. } \\
\text { (Enf. 6). }\end{array}$ \\
\hline
\end{tabular}


Quadro 2 - Categorias temáticas relativas ao eixo "ações de promoção e vigilância em saúde para a população de Lésbicas, Gays, Bissexuais, Travestis e Transexuais". Juazeiro do Norte, Ceará, Brasil - 2018

(conclusão)

\begin{tabular}{|c|c|}
\hline Categorias & Trechos das entrevistas \\
\hline $\begin{array}{l}\text { Ações de cuidado } \\
\text { enviesadas em } \\
\text { função de orientação } \\
\text { sexual não } \\
\text { heterossexual }\end{array}$ & $\begin{array}{l}\text { A grande maioria dos atendimentos são de pessoas com sintomas característicos de IST, como a } \\
\text { Aids, sífilis, Hepatites adquiridas devido à falta de informação ou a questão relacionada à cultura. } \\
\text { (Enf. 4). } \\
\text { Eles são vulneráveis às IST, à Aids, posteriormente a uma tuberculose e assim por diante, porque a } \\
\text { maioria ainda não se cuida como deveria. (Enf. 10). } \\
\text { Os encaminhamentos dependem do caso. Podem precisar das especialidades em urologia, ginecologia, } \\
\text { infectologia ou psicologia para tratar algum problema, porque eles não são aceitos na sociedade e } \\
\text { vítimas de vários preconceitos que acabam desencadeando um transtorno mental. (Enf. 5). }\end{array}$ \\
\hline
\end{tabular}

Fonte: Elaboração própria.

No eixo 3 da Política Nacional de Saúde Integral de LGBT referente à "educação permanente e educação popular em saúde com foco na população LGBT", os profissionais relataram dificuldades em abordar aspectos relativos à saúde dessa população em decorrência de lacunas na formação profissional, embora aspectos valorativos fossem considerados como necessários à garantia do respeito. Além disso, os profissionais desconheciam a existência e/ou diretrizes de uma política para LGBT, sendo as ações incluídas em outros programas e estratégias. Dessa forma, capacitações foram apontadas como essenciais para qualificar o atendimento ao público LGBT.

Quadro 3 - Categorias temáticas relativas ao eixo "educação permanente e educação popular em saúde com foco na população de Lésbicas, Gays, Bissexuais, Travestis e Transexuais”. Juazeiro do Norte, Ceará, Brasil - 2018

(continua)

\begin{tabular}{|c|c|}
\hline Categorias & Trechos das entrevistas \\
\hline $\begin{array}{l}\text { Formação pessoal e } \\
\text { profissional deficitária } \\
\text { para assistência ao } \\
\text { público LGBT }\end{array}$ & $\begin{array}{l}\text { Muitos profissionais não sabem lidar com as pessoas, abordar, tratar com caráter e dignidade. } \\
\text { Tem coisas que a gente não aprende na faculdade; é a vida que nos ensina. Não é porque você é } \\
\text { estudado ou coisa do tipo; é a educação de casa que faz o caráter da pessoa. Então acredito que é } \\
\text { independente da qualificação, capacitação ou dos anos de estudo. (Enf. 1). } \\
\text { As instituições de ensino superior atualmente não capacitam os futuros profissionais com relação } \\
\text { ao grupo LGBT, porque há uma dificuldade em se trabalhar temas transversais e depende } \\
\text { da formação docente. Os egressos são um reflexo do seu corpo docente. Se os professores são } \\
\text { preconceituosos em determinados aspectos, eles vão tender a reproduzir o modelo que aprenderam. } \\
\text { (Enf. 7). }\end{array}$ \\
\hline $\begin{array}{l}\text { Desconhecimento da } \\
\text { política e/ou de suas } \\
\text { diretrizes }\end{array}$ & $\begin{array}{l}\text { A gente chama os usuários para aderir aos programas, às campanhas de prevenção do colo do } \\
\text { útero, de vacinação, mas população LGBT não está sendo chamada porque ainda não está sendo } \\
\text { desenvolvido, pelo Ministério da Saúde, uma campanha, programa ou projeto específico voltado } \\
\text { para esse grupo. (Enf. 9). } \\
\text { Eu sei que existe uma política LGBT, agora estudar e me aprofundar nisso eu nunca fiz. Eu faço } \\
\text { o que tem que fazer na prevenção de IST, na questão do acolbimento, mas não por conhecer a } \\
\text { política. Eu faço isso porque está inserido em outras políticas. (Enf. 4). } \\
\text { Assim como tem a política de saúde do homem, da mulher, da criança, também deveria existir } \\
\text { para LGBT. Já que tem tantas pessoas e casais assim, eles também têm o direito de ter uma política } \\
\text { que os favoreça. (Enf. 12). } \\
\text { Não, eu não conheço. Acredito que deva ter uma política LGBT, mas que não é tida como } \\
\text { prioritária. (Enf. 8). } \\
\text { A Estratégia Saúde da Família e os programas de atenção à saúde são para heterossexuais e não } \\
\text { pra homossexuais. É tanto que não tem nenhuma política de saúde pro LGBT. (Enf. 3). }\end{array}$ \\
\hline
\end{tabular}


Quadro 3 - Categorias temáticas relativas ao eixo "educação permanente e educação popular em saúde com foco na população de Lésbicas, Gays, Bissexuais, Travestis e Transexuais”. Juazeiro do Norte, Ceará, Brasil - 2018

(conclusão)

\begin{tabular}{|l|l|}
\hline Categorias & \multicolumn{1}{c|}{ Trechos das entrevistas } \\
\hline $\begin{array}{l}\text { Educação } \\
\text { permanente como } \\
\text { necessidade para } \\
\text { O atendimento } \\
\text { qualificado ao } \\
\text { público LGBT }\end{array}$ & $\begin{array}{l}\text { Eu acho que começa pela falta de qualificação dos profissionais de saúde pra atender essa } \\
\text { população. É sugestivo que se capacite toda a equipe da ESF sobre a saúde da população LGBT. } \\
\text { (Enf. 2). }\end{array}$ \\
$\begin{array}{l}\text { Tem que começar pela base da ESF, fazer uma capacitação com os agentes comunitários de } \\
\text { saúde, pra eles saberem como abordar esse público, identificar as necessidades, fazer busca ativa } \\
\text { e levantar informações através de um questionário básico, para orientar as açôes de promoção da } \\
\text { saúde. (Enf. 11). } \\
\text { Como os profissionais aprendem uma coisa muito superficial na faculdade, há a necessidade de } \\
\text { capacitação, educação continuada, não somente para o enfermeiro, mas pra toda a equipe. (Enf. 5). }\end{array}$ \\
\hline
\end{tabular}

Fonte: Elaboração própria.

No eixo 4 da Política Nacional de Saúde Integral de LGBT concernente ao "monitoramento e avaliação das ações de saúde para a população LGBT", os profissionais relataram que o desenvolvimento das ações de saúde é impactado pela ausência de recursos e apoio dos gestores, descontinuidade das ações, sobrecarga de atribuições e centralização no enfermeiro. Esses processos são dificultados pela ausência de participação de distintos segmentos sociais na formulação de estratégias e de descentralização das ações.

Quadro 4 - Categorias temáticas relativas ao eixo "monitoramento e avaliação das ações de saúde para a população de Lésbicas, Gays, Bissexuais, Travestis e Transexuais”. Juazeiro do Norte, Ceará, Brasil - 2018

\begin{tabular}{|c|c|}
\hline Categorias & Trechos das entrevistas \\
\hline $\begin{array}{l}\text { Déficit de apoio ao } \\
\text { desenvolvimento de } \\
\text { ações }\end{array}$ & $\begin{array}{l}\text { Tem que ter a base do governo federal, estadual, municipal e a pactuação com os profissionais } \\
\text { de forma contínua e coesa. Não é somente a boa vontade do profissional. É preciso ter subsídios } \\
\text { e recursos para funcionar de forma adequada, fazer um trabalho com qualidade e dar } \\
\text { continuidade. (Enf. 1). } \\
\text { Outro grande desafio é acompanhar e analisar as ações desenvolvidas. Para isso, a gente precisa } \\
\text { estar sendo apoiado pelos gestores em termos de suporte estrutural, material e pessoal. Esse processo } \\
\text { não deve estar centrado no enfermeiro. Toda a equipe tem que estar envolvida. (Enf. 7). } \\
\text { Infelizmente, na realidade das equipes de saúde da família, elas estão sendo pulverizadas por uma } \\
\text { série de demandas, ações e serviços que devem ser ofertados nos programas do Ministério da Saúde, } \\
\text { e lidam com limitaçeses em relação à carga horária de trabalbo e quantitativo de profissionais. } \\
\text { Essas exigências impedem que o profissional tenha uma maior dedicação às ações epidemiológicas, } \\
\text { embora alguns se furtam, por questões que envolvem preconceitos e marginalização. Logo, as ações } \\
\text { terminam por não existir. (Enf. 10). }\end{array}$ \\
\hline
\end{tabular}

Fonte: Elaboração própria.

\section{Discussão}

Os resultados apontaram reduzida assiduidade aos serviços de saúde e baixa adesão às ações pelo grupo LGBT, devido à ausência de uma agenda de cuidados e do envolvimento dos profissionais com as demandas e acolhimento desse público. Este aspecto é resultado 
da estigmatização social, estereótipos relativos às necessidades de saúde e ideias socialmente equivocadas dos profissionais sobre LGBT.

O preconceito contra a orientação sexual não heterossexual, situações discriminatórias ou homofobia percebida nos cuidados em saúde representam as principais barreiras que atrasam ou evitam a procura aos serviços quando LGBT necessitam de assistência. Dessa maneira, problemas e necessidades de saúde de populações com diferentes orientações sexuais terminam não sendo conhecidos pelos profissionais, o que implica na permanência desses em situação de vulnerabilidade ${ }^{(20)}$. Essa dimensão corrobora o conteúdo das falas dos profissionais, que se encontram alicerçadas em representações sociais estereotipadas sobre o grupo e apresentam teor preconceituoso, estigmatizante, discriminatório e excludente, contribuindo para falta de interesse em desenvolver ações específicas para essa população, a despeito da existência da Política Nacional de Saúde Integral de LGBT.

O distanciamento de LGBT da rede pública de saúde ocorre em função da insatisfação, por julgarem esses serviços como inacessíveis e incapazes de dar resolutividade às suas demandas, fazendo com que significativa parcela utilize a rede privada para ter acesso a consultas médicas e exames ${ }^{(21)}$. Essa perspectiva reforça-se, à medida que os entrevistados apontam que a ESF não constitui espaço de atenção à saúde para LGBT. Logo, os profissionais, ao não acolherem as demandas desses usuários e adotarem condutas e posturas não receptivas, robustecem a lógica excludente e contribuem para manutenção da vulnerabilidade programática no âmbito dos serviços de saúde.

A forma como o serviço acolhe e constrói vínculos com o usuário é determinante para a adesão às ações de cuidado. No entanto, nos itinerários em saúde, barreiras impostas à relação entre profissionais e usuários LGBT são evidentes. A dificuldade de comunicação em função da orientação sexual, a incapacidade dos serviços e profissionais de garantir acesso, acolher, escutar, resolver problemas básicos ou referenciar às unidades especializadas e construir vínculos ${ }^{(22)}$, contribui para o afastamento dessa população dos serviços de promoção de saúde. Esse distanciamento, aliado às situações de vulnerabilidade e violações de direitos humanos, tem sido apontado, no processo social, como catalisador do adoecimento e da necessidade de internação, na qual as trajetórias pessoais passam a ter centralidade na lógica hospitalocêntrica ${ }^{(23)}$.

No contexto de cuidados primários, as ações de cuidado reportadas pelos profissionais entrevistados foram enviesadas em função da orientação sexual não heterossexual do usuário, à medida que se restringiram aos aspectos sexuais com foco nas IST, vulnerabilidades e aspectos psicológicos. Essa lógica reducionista é alicerçada na concepção de grupos de risco, na ESF como cenário de atenção heteronormativo e em representações sociais discriminatórias e marginalizantes ${ }^{(8,24)}$. Esse aspecto é interiorizado pelos integrantes do grupo e reproduz-se nos comportamentos de autocuidado adotados e na busca por assistência, que se encontram condicionados à presença de sintomas patológicos ou para rastreio e tratamento de $\operatorname{IST}^{(8)}$.

Em decorrência dessa condição, as estratégias em saúde apontadas pelos profissionais foram centradas em uma lógica curativista, biomédica e epidemiológica, que considera a homossexualidade sob o viés da patologização que necessita estar sujeita a mecanismos de busca ativa e captação para ser alvo de intervenção. Este achado, além de indicar a predominância do modelo biomédico na saúde brasileira, evidencia a utilização de estratégias não condizentes com os princípios da APS e da política LGBT, que têm como foco a promoção da saúde pelo reconhecimento dos determinantes e condicionantes de saúde, o acesso oportuno a atendimento integral e qualificado para redução das desigualdades em saúde ${ }^{(1)}$.

As práticas de enfermagem no âmbito da sexualidade demonstram pouca relação com a promoção da saúde, concretizando-se por meio de orientações acerca da prevenção de IST e uso de métodos contraceptivos ${ }^{(25)}$. A formação profissional ainda se encontra centrada em uma visão 
biologicista, com reducionismo à genitalidade, ênfase na doença e tecnicista do cuidado, com destaque para as tecnologias duras, desconsiderando os determinantes de saúde e as relações sociais imbricadas no processo saúde-doença.

Esse achado materializa-se na prática dos profissionais, nos atendimentos e nas consultas, nos quais se evidenciam dificuldades em abordar a orientação sexual dos usuários. Experiências reportadas por LGBT descrevem que a menor procura pelos serviços de saúde está associada à existência de discriminação e despreparo dos profissionais para lidar com as suas especificidades, além de dificuldades em revelar sua identidade sexual aos profissionais de saúde ${ }^{(6)}$.

Durante a formação acadêmica do enfermeiro, a abordagem da sexualidade nas disciplinas e conteúdos curriculares limita-se a aspectos biológicos ou reprodutivos com viés patologizante e encontra-se marcada pela neutralização dos corpos sexuados, assexualização do sujeito cuidado e da assistência prestada e o ocultamento da temática. O caráter de eventualidade e informalidade ao longo da formação constituem mecanismos geradores de sentimentos como insegurança, angústia e constrangimento no momento do cuidado de enfermagem, bem como reações negativas ou indesejadas que remetem à questão do despreparo dos estudantes para lidar com a sexualidade ${ }^{(26)}$, principalmente se esta foge dos padrões heteronormativos vigentes.

Em face dessa lacuna, os enfermeiros, ao exercerem atividades assistenciais e docentes, acabam reproduzindo o modelo heteronormativo $^{(24)}$ - mais significativo durante sua formação - e suas práticas de cuidado e/ou pedagógicas tendem a ser respaldadas em crenças e valores pessoais $^{(27)}$.

Esse contexto formativo fragilizado é agravado pelo desconhecimento da política LGBT e/ou de suas diretrizes e pela ausência de qualificação profissional continuada que, em conjunto, reforçam a invisibilidade e marginalização das demandas em saúde do público LGBT. Estas passam a ser percebidas como não prioritárias, à medida que existe um perfil de atendimento que se restringe a uma demanda programada baseada em rotinas rígidas e convenientes, voltada para populações e contextos epidemiológicos específicos. Embora conteúdos relativos aos cuidados de saúde voltados a LGBT estejam sendo discutidos, o ensino de políticas específicas para esse público é basicamente inexistente ${ }^{(28)}$.

Para que se possa fornecer cuidados integrais aos usuários, há necessidade de inserção e padronização de conteúdos sobre sexualidade nos currículos de enfermagem $^{(29)}$. Quando se trata de diversidade sexual, a falta de compreensão de enfermeiros pode afetar negativamente o tipo e a qualidade do atendimento recebido, à medida que não se fornece cuidados culturalmente sensíveis aos usuários LGBT $^{(30-31)}$.

Desse modo, estratégias de ensino e programas de treinamento para cuidados de saúde voltados a LGBT podem exercer efeitos positivos e benéficos, ao elevar os conhecimentos, as habilidades e as atitudes de alunos e profissionais, promover competência cultural, sensibilidade e reduzir dificuldades de abordagem nos atendimentos $^{(32-34)}$.

Os entrevistados revelaram ainda que as ações de saúde para a população LGBT são escassas na APS, em decorrência da dificuldade de priorização, operacionalização, apoio e implementação de uma agenda de cuidados que se impõe como desafio ao processo de trabalho na ESF. Estes aspectos fazem prevalecer a lógica de que grupos tidos como minoritários e marginalizados recebem pouca atenção e que o acesso à saúde deve estar condicionado a um perfil de morbimortalidade.

A efetivação de políticas de promoção da equidade depende da capacidade do governo federal de sensibilizar os gestores dos níveis subnacionais; da oferta de condições objetivas das três esferas de governo na pactuação de responsabilidades e financiamento; do grau de organização do movimento social para pressionar governantes para implantação dessas políticas; bem como de sensibilização e qualificação dos profissionais para atuarem com as políticas de promoção da equidade ${ }^{(35)}$.

Por fim, o monitoramento e a avaliação das ações, conforme apontado pelos entrevistados, 
são dimensões que não se efetivam, porque as políticas verticalizadas não atendem às reais necessidades locais e o controle social do público LGBT é inexistente. A participação popular é um importante instrumento de gestão, pela sua capacidade de contribuição com o desenvolvimento e aprimoramento das ações. Entretanto, a participação efetiva é um desafio permanente para operacionalização das políticas públicas no âmbito do SUS ${ }^{(35)}$.

Em função desse quadro de fragilidades institucionais e das deficiências estruturais que permeiam as ações de promoção da equidade, elas correm o risco de se constituir apenas em eventos pontuais em detrimento de uma política permanente ${ }^{(35)}$. Isto evidencia a necessidade de mudança paradigmática na atenção à saúde para alcançar um novo ideário de justiça social, em que todas as pessoas tenham oportunidades justas para atingir o seu potencial de saúde completo $^{(1,15)}$.

Assim, é necessário que os princípios de universalidade, integralidade e equidade constitutivos do SUS e materializados na Política Nacional de Atenção Integral LGBT possam, de fato, promover o enfrentamento das condições excludentes nos serviços de saúde, especialmente na APS, como resultado da homofobia e da heteronormatividade que persiste em se manter na sociedade. Do contrário, continuarão a existir barreiras simbólicas, morais e estéticas que impedem o acesso e a assistência da população LGBT aos serviços de saúde.

Em decorrência de a investigação ter sido conduzida com amostra pequena, composta por apenas uma categoria profissional da equipe multidisciplinar atuante na ESF, e a intencionalidade na forma de recrutamento de participantes adotada, assim como limitações associadas ao estudo podem comprometer a interpretação e generalização dos resultados. Entretanto, os achados oferecem dados importantes sobre a assistência dispensada ao público LGBT na ESF e contribui para o preenchimento de lacunas acerca do assunto.

\section{Conclusão}

Apesar da existência de um plano operativo que fornece subsídios para implementação da Política Nacional de Atenção Integral a LGBT em todos os níveis de atenção à saúde, os cuidados primários a este público são escassos no contexto da ESF.

Neste cenário de atenção, a atuação dos enfermeiros em face de usuários LGBT encontra-se fragilizada em decorrência da baixa assiduidade, estereótipos relativos às necessidades de saúde, barreiras impostas ao acolhimento e comunicação. Diante disso, as ações e estratégias de promoção e vigilância em saúde são enviesadas em função da orientação sexual não heterossexual e influência do modelo biomédico, bem como agravadas por lacunas na formação acadêmica e qualificação profissional, desconhecimento da política e suas diretrizes, déficit de apoio ao desenvolvimento de ações, ausência de controle social nas instâncias de participação, monitoramento e avaliação das ações de saúde.

Desse modo, muito se precisa avançar para que os eixos da política situados em um plano teórico-organizacional sejam não apenas percebidos e incorporados na prática, como também compreendidos como dimensões imprescindíveis à transformação das iniquidades, desigualdades e disparidades em saúde vivenciadas por LGBT. Na APS esse processo envolve a necessidade de mudanças paradigmáticas que ancorem a concepção ampliada de saúde e transcendam aspectos de natureza sócio-histórico e cultural enraizados no processo saúde-doença e nas relações e posturas entre os sujeitos envolvidos na produção do cuidado em saúde e no desenvolvimento de ações e estratégias de promoção da saúde.

\section{Colaborações:}

1. concepção, projeto, análise e interpretação dos dados: Jameson Moreira Belém e Grayce Alencar Albuquerque;

2. redação do artigo e revisão crítica relevante do conteúdo intelectual: Jameson 
Moreira Belém, Maria Juscinaide Henrique Alves, Emanuelly Vieira Pereira, Felice Teles Lira dos Santos Moreira, Glauberto da Silva Quirino e Grayce Alencar Albuquerque;

3. aprovação final da versão a ser publicada: Jameson Moreira Belém, Maria Juscinaide Henrique Alves, Emanuelly Vieira Pereira, Felice Teles Lira dos Santos Moreira, Glauberto da Silva Quirino e Grayce Alencar Albuquerque.

\section{Referências}

1. Fertonani HP, Pires DEP, Biff D, Scherer MDA. The health care model: concepts and challenges for primary health care in Brazil. Ciênc Saúde Colet (Internet). 2015 Jun [cited 2017 Nov 25];20(6):186978. Available from: http://www.scielo.br/pdf/csc/ v20n6/en_1413-8123-csc-20-06-1869.pdf

2. Rocha SA, Bocchi SCM, Godoy MF. Acesso aos cuidados primários de saúde: revisão integrativa. Physis. 2016 Mar;26(1):87-111.

3. Hsieh N, Ruther M. Despite Increased Insurance Coverage, Nonwhite Sexual Minorities Still Experience Disparities In Access To Care. Health Aff. 2017 Oct 1;36(10):1786-94.

4. Barrientos J. Situación social y legal de gays, lesbianas y personas transgénero y la discriminación contra estas poblaciones en América Latina. Sex Salud Soc. 2016;22:331-54.

5. Whitehead J, Shaver J, Stephenson R. Outness, Stigma, and Primary Health Care Utilization among Rural LGBT Populations. PLOS ONE [Internet]. 2016 jan [cited 2017 Nov 26];11(1):e0146139. Available from: https://doi.org/10.1371/journal. pone.0146139

6. Cardoso MR, Ferro LF. Saúde e população LGBT: demandas e especificidades em questão. Psicol ciênc. 2012;32(3):552-63.

7. Lunn MR, Cui W, Zack MM, Thompson WW, Blank MB, Yehia BR. Sociodemographic Characteristics and Health Outcomes Among Lesbian, Gay, and Bisexual U.S. Adults Using Healthy People 2020 Leading Health Indicators. LGBT Health. 2017 Aug 1;4(4):283-94.

8. Garcia CL, Albuquerque GA, Drezett J, Adami F. Health of Sexual Minorities in North-eastern Brazil: Representations, Behaviours and Obstacles. J Hum Growth Dev. 2016;26(1):94-100.
9. Santos AR, Santos RMM, Souza ML, Boery RNSO, Sena ELS, Yarid SD. Bioethical implications in health care for the LGBTT public. Rev bioét. 2015;23(2):400-8.

10. Brasil. Ministério da Saúde. Secretaria Especial de Direitos Humanos. Ministério das Mulheres, da Igualdade Racial e dos Direitos Humanos. Relatório de Violência Homofóbica no Brasil: ano 2013 [Internet]. Brasília; 2016 [cited 2017 Nov 26]. Available from: http://www.sdh.gov.br/assuntos/ lgbt/dados-estatisticos/Relatorio2013.pdf

11. Brignol S, Dourado I, Amorim LD, Kerr LRFS. Vulnerability in the context of HIV and syphilis infection in a population of men who have sex with men (MSM) in Salvador, Bahia State, Brazil. Cad Saúde Pública. 2015;31(5):1-14.

12. Sousa PJ, Ferreira LOC, Sá JB. Estudo descritivo da homofobia e vulnerabilidade ao HIV/Aids das travestis da Região Metropolitana do Recife, Brasil. Ciênc Saúde Colet. 2013 maio;18(8):2239-51.

13. Natarelli TRP, Braga IF, Oliveira WA, Silva MAI. O impacto da homofobia na saúde do adolescente. Esc Anna Nery. 2015 Oct-Dec;19(4):664-70.

14. Ceará AT, Dalgalarrondo P. Transtornos mentais, qualidade de vida e identidade em homossexuais na maturidade e velhice. Rev psiquiatr clín. 2010;37(3):118-23.

15. Popadiuk GS, Oliveira DC, Signorelli MC. The National Policy for Comprehensive Health of Lesbians, Gays, Bisexuals and Transgender (LGBT) and access to the Sex Reassignment Process in the Brazilian Unified Health System (SUS): progress and challenges. Ciênc saúde Colet. 2017 May;22(5):1509-20.

16. Brasil. Ministério da Saúde. Secretaria de Gestão Estratégica e Participativa. Departamento de Apoio à Gestão Participativa. Política Nacional de Saúde Integral de Lésbicas, Gays, Bissexuais, Travestis e Transexuais [Internet]. Brasília; 2013 [cited 2017 Nov 26]. Available from: http://bvsms. saude.gov.br/bvs/publicacoes/politica_nacional_ saude_lesbicas_gays.pdf

17. Baptiste-Roberts K, Oranuba E, Werts N, Edwards LV. Addressing Health Care Disparities Among Sexual Minorities. Obstet Gynecol Clin North Am. 2017 Mar;44(1):71-80.

18. Minayo MCS. Amostragem e saturação em pesquisa qualitativa: consensos e controvérsias. Rev Pesq Qualitativa. 2017 Apr;5(7):1-12. 
19. Carlomagno MC, Rocha LC. Como criar e classificar categorias para fazer análise de conteúdo: uma questão metodológica. Rev Eletr Ciênc Polít. 2016;7(1):173-88.

20. Cele NH, Sibiya MN, Sokhela DG. Experiences of homosexual patients' access to primary health care services in Umlazi, KwaZuluNatal. Curationis. 2015 Sep;38(2):1-9.

21. Carvalho LS, Philippi MM. Percepção de lésbicas, gays e bissexuais em relação aos serviços de saúde. Universitas: Ciênc Saúde. 2013 jul/dez;11(2):83-92.

22. Garuzi M, Achitti MCO, Sato CA, Rocha SA, Spagnuolo RS. Acolhimento na Estratégia Saúde da Família: revisão integrativa. Rev panam salud pública. 2014;35(2):144-9.

23. Maffacciolli R, Oliveira DLLC, Brand EM. Vulnerabilidade e direitos humanos na compreensão de trajetórias de internação por tuberculose. Saúde Soc. 2017;26(1):286-99.

24. Enson S. Causes and consequences of heteronormativity in healthcare and education. British J Sch Nurs. 2015;10(2):73-8.

25. Nogueira IS, Rodrigues DMMR, Labegalini CMG, Lopes MCL, Baldissera VDA. A percepção e formação dos acadêmicos de enfermagem acerca da sexualidade humana. Rev Fund Care [Internet]. 2017 jul/set [cited 2017 Nov 26];9(3):614-9. Available from: http://www.seer.unirio.br/index. $\mathrm{php} /$ cuidadofundamental/article/view/5562/pdf

26. Sehnem GD, Ressel LB, Junges CF, Silva FM, Barreto CN. A sexualidade na formação acadêmica do enfermeiro. Esc Anna Nery. 2013 jan/mar;17(1):90-6.

27. Andrade CAA, Lima Neto ER, Loureiro AR, Araújo EC. A diversidade sexual e as práticas pedagógicas do enfermeiro na docência. Rev Enferm UFPE [Internet]. 2017 Nov [cited 2017 Nov 26];11(11):1-2. Disponível em: https://periodicos.ufpe.br/revistas/ revistaenfermagem/article/view/230727/pdf_1
28. Cornelius JB, Enweana I, Alston CK, Baldwin DM. Examination of Lesbian, Gay, Bisexual, and Transgender Health Care Content in North Carolina Schools of Nursing. J Nurs Educ. 2017 Apr;56(4):223-6.

29. Aaberg V. The state of sexuality education in baccalaureate nursing programs. Nurse Educ Today. 2016 Sep;44:14-9.

30. Carabez R, Scott M. 'Nurses don't deal with these issues': nurses' role in advance care planning for lesbian, gay, bisexual and transgender patients. J Clin Nurs. 2016 Dec;25(23-24):3707-15.

31. Carabez R, Pellegrini M, Mankovitz A, Eliason M, Ciano M, Scott M. "Never in All My Years...": Nurses' Education About LGBT Health. J Prof Nurs. 2015 Jul-Aug;31(4):323-9.

32. Sung SC, Jiang HH, Chen RR, Chao JK. Bridging the gap in sexual healthcare in nursing practice: implementing a sexual healthcare training programme to improve outcomes. J Clin Nurs. 2016 Oct;25(19-20):2989-3000.

33. Strong KL, Folse VN. Assessing undergraduate nursing students' knowledge, attitudes, and cultural competence in caring for lesbian, gay, bisexual, and transgender patients. J Nurs Educ. 2015 Jan;54(1):45-9.

34. Carabez R, Pellegrini M, Mankovitz A, Eliason MJ, Dariotis WM. Nursing students' perceptions of their knowledge of lesbian, gay, bisexual, and transgender issues: effectiveness of a multipurpose assignment in a public health nursing class. J Nurs Educ. 2015 Jan;54(1):50-3.

35. Siqueira SAV, Hollanda E, Motta JIJ. Políticas de Promoção de Equidade em Saúde para grupos vulneráveis: o papel do Ministério da Saúde. Ciênc Saúde Colet. 2017;22(5):1397-406.

Recebido: 15 de maio de 2018

Aprovado: 13 de novembro de 2018

Publicado: 14 de janeiro de 2019

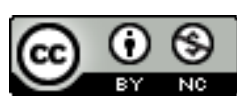

A Revista Baiana de Enfermagem utiliza a Licença Creative Commons - Atribuição-NãoComercial 4.0 Internacional. https://creativecommons.org/licenses/by-nc/4.0/

Este artigo é de acesso aberto distribuído sob os termos da Licença Creative Commons (CC BY-NC). Esta licença permite que outros remixem, adaptem e criem a partir do seu trabalho para fins não comerciais. Embora os novos trabalhos tenham de lhe atribuir o devido crédito e não possam ser usados para fins comerciais, os usuários não têm de licenciar esses trabalhos derivados sob os mesmos termos. 